\title{
CONFlict Analysis For Project AND MATURity MANAGEMENT
}

\author{
AZARov, V.\& CHEKMAREV, A.
}

Abstract: Conflicts are widely used in management as engine for development and a tool for collecting information about current processes. But what kind of information can we get by analyzing conflicts, arising during information technology project and how can we use it? Could we measure conflict characteristics? Are these conflicts unavoidable? Could we use conflict information for maturity and capability evaluation? According to ISO 9000 we should provide interim control of projects flow to achieve higher quality. But how can we do that between or before control milestones of the project? Could we use conflict information for interim control? The article presents results of implementation of new method for project interim audit, based on quantitative analysis of conflicts. Provided case study also demonstrates results of the conflict evaluation method application for Capability Maturity Model Integration appraisal.

Keywords: quality, maturity model, project, CMMI
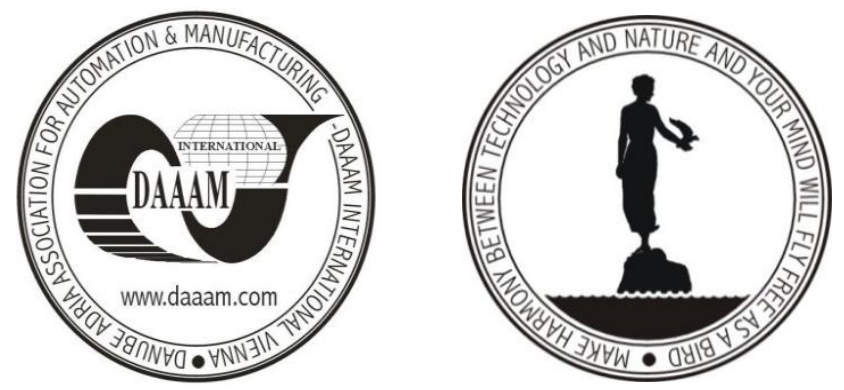

Authors' data: Univ.Prof. Dr.techn. Vice-rector. Azarov, V[ladimir]*; Dr.techn. Chekmarev, A[natoly]*, * Moscow Institute of Electronics and Mathematics Higher School of Economics, Trekhsviatitelskii pereulok, 3, Moscow, Russia, vazarov@ hse.ru, anatolii_chekmar@mail.ru.

This Publication has to be referred as: Azarov, V[ladimir] \& Chekmarev, A[natoliy] (2014). Conflict Analysis for Project and Maturity Management, Chapter 46 in DAAAM International Scientific Book 2014, pp.577-584, B. Katalinic (Ed.), Published by DAAAM International, ISBN 978-3-901509-98-8, ISSN 1726-9687, Vienna, Austria

DOI: 10.2507/daaam.scibook.2014.46 


\section{Introduction}

A lot of complex IT projects at the recent times are completed unsuccessfully. For example, according to report of the Standish Group in 2009 only $32 \%$ of projects met time, budget and quality requirements, $24 \%$ were interrupted before completion.

Due to that fact research of IT project management improvement methods becomes important.

According to ISO 9000 interim control of projects and process flow for higher quality should be provided. But that task is very tough outside milestones and recognizable physical results. Conflicts arise throughout life of a project and could provide information at request, so could be used for interim control.

International standards and common methods of project and process management for example PMI Project Management Body of Knowledge, Capability Maturity Model Integration, pay apparent attention to conflict management during project implementation. Conflict is considered as an inevitable phenomenon or process which should be effectively managed and having significant influence on project results. "...Completion of projects may require several years, and they can be difficult to manage under the best of circumstances. If organizational conflict is superimposed upon the normal project management difficulties, successful project outcomes are rendered immensely more difficult..." (Sutterfield, et. al., 2007).

Every project is a process creating unique outcomes and changing organization. It inevitably forces subsystems of organization to adopt changes, which are divergent from their goals and current way of work. Need of adaptation creates stress and tension (Venda, 1990). Stress created by project is recognized as negative emotions and conflict with project team by employees. So conflict is unavoidable. High level stress could lead to crucial loss of effectiveness of a system (Venda, 1990). Consequently project manager should avoid high level of conflicts but absence of conflict demonstrates lack of adaptation processes and project progress.

In management theory conflicts are widely considered as development engine and an ongoing process analysis tool. In (Kurtuhuz, et. al., 2011) is posited that “...conflict will undoubtedly arise in the management team, both functional and dysfunctional. The form of conflict that is productive is cognitive conflict, which is task oriented and focused on discussing and challenging diverse perspectives... The opposite form of conflict is affective conflict, which is more emotional based. When considering conflict, the key to ensuring a high performing management team is making sure that conflict is of the cognitive variety, based on critical thinking and focused on tasks, while removing the affective conflict, that which is based on emotion...."

The higher level of the conflict the lower quality of the project outcomes (Barki \& Hartwick, 2001). Three dimensions of conflict have been identified: interdependence, disagreement and interference (Barki \& Hartwick, 2001). Consequently they could be used to measure level of conflict and predict quality of project outcomes. It could be used for creating of early alerts. 
"...Process-based conflict deals with tension that stems from how tasks should be completed..." (Sutterfield, et. al., 2007). The mentioned paper posited conflicts of processes. Processes of a project are well classified by PM PMBOK. They are conducted in the midst of current work processes classified for example by CMMI. High level of conflict demonstrates need for adaptation of conflicting processes and consequently low maturity of them. Received information about process conflicts helps to select priorities during revamp of project and organization.

Project outcomes quality is function of several main parameters: Project group capability, Organization processes capability, Project complexity, Level of conflicts and Style of conflicts resolving (Barki \& Hartwick, 2001). That statement could be used for various purposes. If Project group capability, Organization processes capability and Project complexity are measured and constant than project outcomes quality could by predicted via conflict characteristics. If Project outcomes quality, Project group capability, Project complexity are constant than Organization processes capability (maturity level) could by measured via project conflict characteristics.

Although there is extensive research regarding conflicts there is lack of research examining methods of conflicts level and conflicts resolving effectiveness measuring and interpretation. This study tries to fill a void in the project management literature by proposing a new method of interim control of IT projects and maturity assessment via conflict measurements. Besides that, proposed approach allows positing that project manager can and should manage level of conflicts. Low level of conflict demonstrates lack of project progress and gives opportunity to select priorities during revamp of project and organization.

\section{Conflicts in project management}

PMI PMBOK (Project Management Institute Project Management Body of Knowledge) gives very structured description of conflict management in the chapter "Project human resource management". According to PMBOK "Successful conflict management results in greater productivity... Conflict is natural and forces a search for alternatives. Conflict is a team issue, Openness resolves conflict, Conflict resolution should focus on issues, not personalities and Conflict resolution should focus on the present, not the past". Besides, PMBOK defines six general techniques for resolving conflicts: Withdrawing/Avoiding (retreating from actual or potential conflict situation, Smoothing/Accommodating (emphasizing areas of agreement rather than areas of difference), Compromising (searching for solutions that bring some degree of satisfaction to all parts), Forcing (pushing one's viewpoint at the expense of others), Collaborating (incorporating multiple viewpoints and insights from different perspectives), Confronting/Problem solving (treating conflict as a problem to be solved by examining alternatives).

PMBOK suggests managing only of team conflicts and neglect other types of conflict for example conflicts of Sponsor and Project manager. As a result PMBOK unfortunately could not provide an overall description and guideline for this issue. 
The theory of complex systems and system analysis share approach to conflict issues, which interpret any conflict as a natural process of interaction of two or more developing and co-adapting complex systems (Venda, 1990), (Druzhinin, 1989). Arising of conflicts is caused by systems interaction or changes of inner subsystems of the organization system. Project development is inevitably accompanied or followed by conflicts that are not negative per se.

A conflict can be considered "good" or "bad" depending on its characteristics level and result (style of resolving). But the main characteristic is reasonability of the conflict - some of them have no system-related reasons.

Various conflict resolving techniques have different potential for adaptation of organization to project and its results. Some of them reject adaptation and could make the project a "mission impossible" or lower its quality level.

The level of conflict allows evaluating the amount of changes and ability of the organizational system (maturity of the system) to adopt changes produced by the project of such complexity. Resolution style and stakeholder's interaction can help to predict the quality level of the upcoming project results or its part.

This suggestion provides the possibility to develop a method for on-line evaluation of project implementation effectiveness based on quantitative conflict evaluation instead of final or milestones control.

Conflicts can provide valuable information about project implementation. Projects are implemented in an existing organizational system interacting with its processes. So each project implementation process with arising conflicts can be used to get information not only about itself but also about effectiveness and capability of interacting subsystems and processes, about their maturity.

There are recommendations about conflict management in almost every process area description of CMMI.

Thereby the existence of conflicts, there severity and style of resolving are directly interconnected with maturity level and could be used for its recognition. Meanwhile official documentation of CMMI and accompanying publications contain no information about conflict evaluation and classification.

Besides quantitative conflict characteristics could be used as additional metrics of processes such as "Quantitative Project Management" on the higher levels of maturity.

CMMI is widely used in the world. Consequently developing new maturity level evaluation methods is a very relevant task.

Surely conflict evaluation methods could be used in appraisal of different processbased standards of IT and project management (ISO 20000, COBIT, ITIL, etc).

\section{Measurement of conflicts}

According to the system approach conflict management is management of adaptation of organization to outer changes and co-adaptation of its subsystems to each other. It is management of development of organization. Conflicts can provide valuable and objective information as they allow comparing subjective opinions. Taking this point into account, the following techniques should be developed: Measuring of 
conflict intensity, Measuring of conflict effectiveness of resolving, Identifying the conflict's origin, Evaluating of maturity level.

All the information could be taken from the people taking part in the project. Man is a very universal and effective sensor but his interpretation should be corrected. Accordingly, methods of The Theory of Expert Estimation can be used to get precise scores. Adopted Likert 5 levels scale could be used to get raw data.

Conflicts are recognized as interpersonal phenomenon. There are four metrics, offered by (Barki \& Hartwick, 2001) to evaluate the level of conflict: Level of interdependence, Level of disagreements, Level of intervention, Level of negative emotions.Conflict resolving effectiveness could be measured by evaluation of using by the stakeholders of different style of conflict. Some of them are directed to adaptation in interacting while the others are not. Evaluation of presence of Compromising, Collaborating and Problem solving style provides the required score of effectiveness of conflict resolving.

Unfortunately due to common low level of maturity (on the lowest levels processes could not be defined) and use of different project management standards stakeholders couldn't be asked directly about the problematic area of processes during project implementation and in organization, which causes conflicts. Consequently a more complex technique has to be developed implementing universal process classification and providing possibility to identify a problem-causing process by analyzing the project phase information. Evaluation of maturity level could be done by comparing the level of conflicts and effectiveness of their resolving during the project. This article provides results of the above-mentioned method implementation in complex IT project carried out in one of the biggest Russian financial institution.

\section{Project management and the maturity model}

The goal of the project was to develop an automated system for online position, PnL calculation and limits control for FX (currency exchange deals) and securities deals of treasury department. Overall project implementation period was 18 month. The first 6 - months phase of the project was analyzed - FX deals calculations, which included 4 main stages:

1. Defining and confirming of the project purposes.

2. Creating of the project team and base plan of work.

3. Design, software development and implementation.

4. Testing and formal acceptance.

Questionnaire was filled in by the bank divisions-stakeholders and project manager, which were the sides of the conflicts. All the scores, received from the sides of conflicts were averaged to reduce subjectivity. Unified classification of the project processes areas included in questionnaire was: Functional/technical, Organizational, Planning, Documentation, Testing and acceptance, Finance. Comparison of this unified consolidated definitions and stage of project allowed exact mapping of a project 
Azarov, V. \& Chekmarev, A.: Conflict Analysis for Project and Maturity Manageme... processes (according to PMI PMBOK and CMMI) which caused conflicts and hence had the lowest maturity/capability level.

\begin{tabular}{|l|l|c|c|c|c|c|}
\hline № & Scores & $\begin{array}{c}\mathbf{1} \\
\text { stage }\end{array}$ & $\begin{array}{c}\mathbf{2} \\
\text { stage }\end{array}$ & $\begin{array}{c}\mathbf{3} \\
\text { stage }\end{array}$ & $\begin{array}{c}\mathbf{4} \\
\text { stage }\end{array}$ & $\begin{array}{c}\text { Project } \\
\text { average }\end{array}$ \\
\hline 1. & Conflict intensity & 1,19 & 0,99 & 1,00 & 1,25 & 1,11 \\
\hline 2. & Resolving effectiveness & 2,61 & 2,95 & 2,95 & 2,64 & 2,79 \\
\hline 3. & Maturity & 1,13 & 2,28 & 1,84 & 1,47 & 1,13 \\
\hline
\end{tabular}

Tab. 1. Level of conflict intensity, resolving effectiveness and maturity in different project stages

To check the scores simplified CMMI evaluation of IT processes maturity level was done (only second level processes were checked). Analysis confirmed that some of the processes required for the 2-d level were not implemented. So that quantitative conflict scores are likely to be proved.

\begin{tabular}{|r|l|l|}
\hline № & Processes & Evaluation (capability level) \\
\hline 1. & Configuration Management & Initial (not defined, not repeatable) \\
\hline 2. & Project Planning & $\begin{array}{l}\text { Initial (planning of resources is absent, } \\
\text { milestones are not set) }\end{array}$ \\
\hline 3. & Project Monitoring and Control & $\begin{array}{l}\text { Initial (monitoring is subjective, not } \\
\text { repeatable and planned) }\end{array}$ \\
\hline 5. & Requirements Management & $\begin{array}{l}\text { Initial (regulations or repeatable } \\
\text { process are absent) }\end{array}$ \\
\hline 6. & $\begin{array}{l}\text { Process and Product Quality } \\
\text { Assurance }\end{array}$ & $\begin{array}{l}\text { Initial (user acceptance testing is } \\
\text { implemented without any regulations) }\end{array}$ \\
\hline 7. & Supplier Agreement Management & $\begin{array}{l}\text { Managed (there are regulations for } \\
\text { agreement management and decision } \\
\text { making) }\end{array}$ \\
\hline
\end{tabular}

Tab. 2. Processes of CMMI for Development of the 2-d level 


\begin{tabular}{|c|c|c|c|c|c|c|c|}
\hline \multicolumn{5}{|c|}{ DAAAM INTERNATIONAL SCIENTIFIC BOOK 2014} & \multicolumn{2}{|c|}{ pp. 577-584 } & Chapter 46 \\
\hline № & Process area & Score & 1 stage & 2 stage & 3 stage & 4 stage & Average \\
\hline \multirow[t]{3}{*}{1.} & \multirow{3}{*}{$\begin{array}{l}\text { Functional/ } \\
\text { technical }\end{array}$} & Intens. & 1,28 & 1,00 & 0,99 & 1,17 & 1,11 \\
\hline & & Effectiv. & 2,17 & 2,34 & 2,13 & 2,06 & 2,17 \\
\hline & & Maturity & 1,70 & 2,34 & 2,15 & 1,76 & 1,95 \\
\hline \multirow[t]{3}{*}{2 . } & \multirow[t]{3}{*}{ Organizational } & Intens. & 1,34 & 1,14 & 0,99 & 1,20 & 1,17 \\
\hline & & Effectiv. & 1,50 & 2,6 & 2,63 & 1,76 & 2,12 \\
\hline & & Maturity & 1,12 & 2,28 & 2,66 & 1,47 & 1,81 \\
\hline \multirow[t]{3}{*}{3.} & \multirow[t]{3}{*}{ Planning } & Intens. & 1,22 & 1,04 & 0,96 & 1,19 & 1,10 \\
\hline & & Effectiv. & 2,71 & 2,57 & 3,39 & 2,18 & 2,71 \\
\hline & & Maturity & 2,22 & 2,47 & 3,53 & 1,83 & 2,46 \\
\hline \multirow[t]{3}{*}{4.} & \multirow[t]{3}{*}{ Documentation } & Intens. & 0,94 & 0,84 & 0,95 & 1,21 & 0,99 \\
\hline & & Effectiv. & 4,00 & 3,19 & 2,99 & 3,75 & 3,48 \\
\hline & & Maturity & 4,26 & 3,80 & 3,15 & 3,10 & 3,52 \\
\hline \multirow[t]{3}{*}{5.} & \multirow{3}{*}{$\begin{array}{l}\text { Testing and } \\
\text { acceptance }\end{array}$} & Intens. & 1,06 & 0,90 & 1,07 & 1,55 & 1,14 \\
\hline & & Effectiv. & 2,00 & 2,92 & 1,97 & 2,34 & 2,31 \\
\hline & & Maturity & 1,89 & 3,24 & 1,84 & 1,51 & 2,03 \\
\hline \multirow[t]{3}{*}{6.} & \multirow[t]{3}{*}{ Finance } & Intens. & 1,23 & 0,89 & 0,90 & 1,00 & 1,01 \\
\hline & & Effectiv. & 3,29 & 4,19 & 4,59 & 3,75 & 3,96 \\
\hline & & Maturity & 2,67 & 4,71 & 5,10 & 3,75 & 3,92 \\
\hline
\end{tabular}

Tab. 3. Conflict intensiveness, conflict resolving effectiveness in process areas during project stages

Evaluation of conflict intensiveness and conflict resolving effectiveness (in process areas during project stages (above) confirms the results of comparison of CMMI and conflict scores.

\section{Conclusion}

There are some interesting topics should be examined in future research for example, dependence between maturity level and the conflict characteristics changing curve. Besides that some automated system for collecting data and results interpretation should be developed. But some conclusions are to be presented:

- The evaluation method offered proved to be useful. It provides repeatable, objective scores, which can be used for project monitoring and IT processes and services maturity level evaluation. Hence the scores received can be used for instant reacting and long-term measures/strategy development.

- Questionnaire developed was well understood and provided enough information for analysis.

- The scores received can be used as metrics for comparing effectiveness/maturity of different types of processes.

- Level of maturity can be used as threshold value in project monitoring based on conflict characteristics. For example if the conflict score of maturity received is much lower then the results of CMMI appraisal value then the project complexity probably exceeds the organization's possibilities given its current maturity level and the scope of the project objectives has to be reduced. 
- The study carried out showed that the special software for receiving data of questionnaire and its analysis should be developed for effective monitoring of real projects - during significantly simplified investigation more than 1300 values received from only four stakeholders were processed for only one stage of the project.

\section{References}

Azarov, V.N. (2000). Quality management. Volume 2, Published by MIEM, Moscow, 2000

Barki, H., \& Hartwick, J. (2001). Interpersonal conflict and its management in information system development, MIS Quarterly, Vol.25, No.2 (June, 2001), pp. 195228

Brown, J. \& Day, R. (1981). Measures of Manifest Conflict in Distribution Channels, Journal of Marketing Research No.18, 1981, pp. 263-274

Chekmarev, A.V. (2011). IT - Maturity model. Quality. Innovations. Education No.3. March 2011. p. 40-49

Chekmarev, A.V. (2011). Use of conflict analysis for project management and process maturity evaluation according to CMMI, Education and science automation No.4, April 2011., p. 86-94

Chekmarev, A.V.\& Azarov, V.N. (2012). Conflict analysis for project management and maturity evaluation according to CMMI and PMI PMBOK, LAP LAMBERT Academic Publishing, 2012, ISBN: 3848424975

Cosier, R. A. \& Dalton, D. R. (1990) Positive Effects of Conflict: A Field Assessment, The International Journal of Conflict Management (1), 1990, pp. 81-92

Curtis, B.; Krasner, H. \& Iscoe N. (1988). A Field Study of the Software Design Process for Large Systems, Communications of the ACM, No.31, 1988, pp. 1268-1287 Deutsch, M. (1990). Sixty Years of Conflict, International Journal of Conflict Management No.1, 1990, pp. 237-263

Druzhinin, V.V. (1989). Conflict theory essentials, Radio and communications Kurtuhuz, A.; Vasilescu, I., Lupu, F.; Lupu, A.; Radu, D \& Kurtuhuz, M. (2011). The manager role in decision making. Annals of DAAAM for 2011 \& Proceedings of the 22nd International DAAAM Symposium, Volume 22, No. 1, ISSN 1726-9679 ISBN 978-3-901509-83-4, Published by DAAAM International, Vienna, Austria, EU, 2011. Norfolk, D. (2009). Managing capability and maturity, Bloor Research, 20th February 2009

Sutterfield, S. (2007). How not to manage a project: conflict management lessons learned from a DOD case study, Journal of Behavioral and Applied Management, Vol. 8, No. 3 May 2007, ISSN 1930-0158, pp. 218- 237

Venda, V.F. (1990). Hybrid intelligence systems, Machinostroenie, Moscow Verzuh, E. (2010). Project management, Dialectica, Moscow 